\title{
Predicting C282Y homozygote genotype for hemochromatosis using serum ferritin and transferrin saturation values from 44,809 participants of the HEIRS Study
}

\author{
Andrew Lim MD ${ }^{1}$, Mark Speechley $\mathrm{PhD}^{2}$, Paul C Adams MD ${ }^{1}$
}

A Lim, M Speechley, PC Adams. Predicting C282Y homozygote genotype for hemochromatosis using serum ferritin and transferrin saturation values from 44,809 participants of the HEIRS Study. Can J Gastroenterol Hepatol 2014;28(9):502-504.

INTRODUCTION: The simultaneous interpretation of serum ferritin level and transferrin saturation has been used as a clinical guide to diagnose genetic hemochromatosis. The Hemochromatosis and Iron Overload Screening (HEIRS) Study screened 101,168 North American participants for serum ferritin level and transferrin saturation, and C282Y genotyping for the HFE gene.

METHODS: Logistic regression involving a subsample of Caucasians $(n=44,809)$ was used to predict individual probabilities of HFE C282Y homozygosity using serum ferritin and transferrin saturation values. Men $(n=17,323)$ and women $(n=27,486)$ were analyzed separately. Regression equations were evaluated using area under the curve from ROC analysis and variance explained by Nagelkerke's pseudo R-squared. An Android smartphone App and website application were developed to provide physicians with easy access to predicting C282Y homozygosity of the HFE gene.

RESULTS: The logistic equation had an area under the ROC curve of 0.91 for men and 0.89 for women. The pseudo R-squared was 0.44 for men and 0.34 for women. An example analysis was a Caucasian man with a transferrin saturation of $50 \%$ and a ferritin level of $500 \mu \mathrm{g} / \mathrm{L}$, who had a $1.3 \%$ (95\% CI $1.1 \%$ to $8.8 \%)$ probability of being a $\mathrm{C} 282 \mathrm{Y}$ homozygote.

CONCLUSIONS: A large primary care-based sample of 44,809 participants contributed to the development of a new computer/smartphone tool that predicts the probability of being a $\mathrm{C} 282 \mathrm{Y}$ homozygote of the $\mathrm{HFE}$ gene from serum ferritin and transferrin saturation values.

Key Words: Haemochromatosis; Hemochromatosis; Iron overload
Prédire le génotype homozygote $\mathrm{C} 282 \mathrm{Y}$ de l'hémochromatose à l'aide des valeurs de ferritine sérique et de saturation de la transferrine de 44809 participants à l'étude HEIRS

INTRODUCTION : L'interprétation simultanée du taux de ferritine sérique et de la saturation de la transferrine sert de guide clinique pour diagnostiquer l'hémochromatose génétique. Dans le cadre de l'étude HEIRS sur le dépistage de l'hémochromatose et de la surcharge en fer, des chercheurs ont procédé au dépistage du taux de ferritine sérique et de la saturation de la transferrine ainsi qu'au génotypage C282Y du gène HFE chez 101168 participants nord-américains.

MÉTHODOLOGIE : Les chercheurs ont recouru à la régression logistique d'un sous-groupe de participants blancs $(n=44809)$ pour prédire les probabilités individuelles d'homozygotie C282Y HFE à l'aide des valeurs de ferritine sérique et de saturation de la transferrine. Ils ont analysé les hommes $(n=17323)$ et les femmes $(n=27486)$ séparément. Ils ont évalué les équations de régression à l'aide de l'aire sous la courbe tirée de l'analyse ROC et expliqué la variance au moyen du pseudo-R carré de Nagelkerke. Ils ont mis au point une application Android pour téléphone intelligent et pour site Web afin de fournir aux médecins un moyen facile de prédire l'homozygotie C282Y du gène HFE.

RÉSULTATS : L'équation logistique avait une aire sous la courbe ROC de 0,91 pour les hommes et de 0,89 pour les femmes. Le pseudo- $R$ carré était de 0,44 pour les hommes et de 0,34 pour les femmes. Par exemple, dans une analyse, un homme blanc avait une saturation de transferrine de $50 \%$ et un taux de ferritine de $500 \mu \mathrm{g} / \mathrm{L}$; sa probabilité d'être homozygote C282Y s'élevait à 1,3\% (95 \% IC 1,1\% à 8,8\%).

CONCLUSIONS : Un vaste échantillon de 44809 participants à des soins de première ligne ont contribué à l'élaboration d'un nouvel outil pour ordinateur et téléphone intelligent qui prédit la probabilité d'être homozygote $\mathrm{C} 282 \mathrm{Y}$ au gène $\mathrm{HFE}$ à partir des valeurs de ferritine sérique et de saturation de la transferrine.
W emochromatosis is one of the most common genetic diseases in 1 Caucasian populations; the typical genotype (C282Y mutation of the HFE gene) is observed in one in 227 Caucasians (1). In many affected patients, an elevation in both serum transferrin saturation and serum ferritin values is observed; however, the degree of elevation varies widely and there are nonexpressing C282Y homozygotes with normal serum ferritin levels and transferrin saturation. Many patients are overdiagnosed with hemochromatosis based on elevated values of these iron tests, and serum ferritin level is often elevated for other reasons such as inflammation, daily alcohol use and obesity (2). The simultaneous interpretation of serum ferritin and transferrin saturation values is a common clinical task in the approach to the diagnosis of hemochromatosis (3). In the present study, we developed logistic regression equations to predict the $\mathrm{C} 282 \mathrm{Y}$ genotype from a large primary care-based population sample of Caucasian participants.

\section{METHODS}

The study design and overall results of the Hemochromatosis and Iron Overload Screening (HEIRS) Study have been previously reported $(1,4)$. The HEIRS Study was approved by all local institutional review boards. Participants $\geq 25$ years of age who gave informed consent were recruited from five field centres that, by design, served ethnically and socioeconomically diverse populations. All participants were screened for serum unsaturated iron-binding capacity, serum iron and serum ferritin levels (without intentional fasting), and genotyping to detect the common C282Y and H63D mutations of the HFE gene. Participants who, at recruitment, reported a previous diagnosis of hemochromatosis or iron overload (treated or untreated) were excluded. The present project used only participants self-identified as Caucasian because C282Y-linked hemochromatosis is extremely rare in non-Caucasians.

\footnotetext{
${ }^{1}$ Department of Medicine; ${ }^{2}$ Department of Epidemiology $\mathcal{G}$ Biostatistics and Schulich Interfaculty Program in Public Health, Western University, London, Ontario

Correspondence: Dr Paul C Adams, Department of Medicine, University Hospital, 339 Windermere Road, London, Ontario N6A 2 E8.

Telephone 519-685-8500 ext 35375, fax 519-663-3549, e-mail padams@uwo.ca

Received for publication February 23, 2014. Accepted September 8, 2014
} 


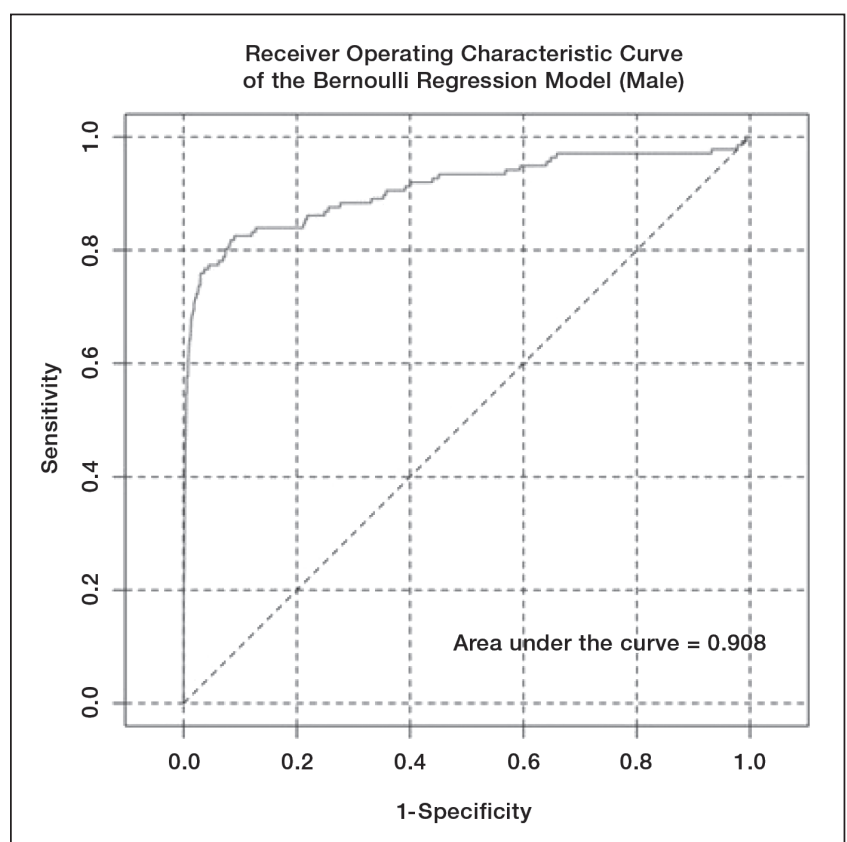

Figure 1) ROC curve for the Bernoulli regression output for men to predict C282Y homozygotes in 17,323 Caucasian men from the Hemochromatosis and Iron Overload Screening (HEIRS) Study. The area under the curve was 0.908 and the Nagelkerke pseudo R-squared was 0.44

A Bernoulli regression model was fitted to the population-based HEIRS data. The regression model had the binary response variable C282Y homozygote $(0,1)$, and continuous explanatory variables serum ferritin level and transferrin saturations (C282Y transferrin saturation + ferritin). Analysis was performed using R Statistical Software. The amount of variance in the response variable explained by the model was estimated using Nagelkerke's pseudo R-squared statistic; the predictive accuracy was estimated using ROC curves. Two-dimensional plots were generated, one with a fixed transferrin saturation and increasing ferritin level, the other with a fixed ferritin level and increasing transferrin saturation.

A free Android smartphone application was developed to enable clinicians to input serum ferritin and transferrin saturation values to obtain the probability of the patient being a C282Y homozygote with a 95\% CI. A website calculator was also developed (http://lim.brichacek.ca/services.html).

\section{RESULTS}

The Bernoulli regression equations are presented below $(\mathrm{P}=$ probability of being a $\mathrm{C} 282 \mathrm{Y}$ homozygote, $\mathrm{F}=$ serum ferritin level, $\mathrm{TS}=$ transferrin saturation).

$\operatorname{Men}(\mathrm{n}=17,323)$

$P(F, T S)=\frac{100}{1+e^{-1 \cdot(-9.6909061643+0.0009248193 \cdot F+0.0976232890 \cdot T S)}}$

Women $(n=27,486)$

$P(F, T S)=\frac{100}{1+e^{-1 \cdot(-9.6909061643+0.0009248193 \cdot F+0.0976232890 \cdot T S)}}$

The ROC curves for the Bernoulli equations to predict C282Y homozygosity are shown in Figures 1 and 2. The probability of being a C282Y homozygote with an increasing serum ferritin level and transferrin saturation is shown in Figures 3 and 4.

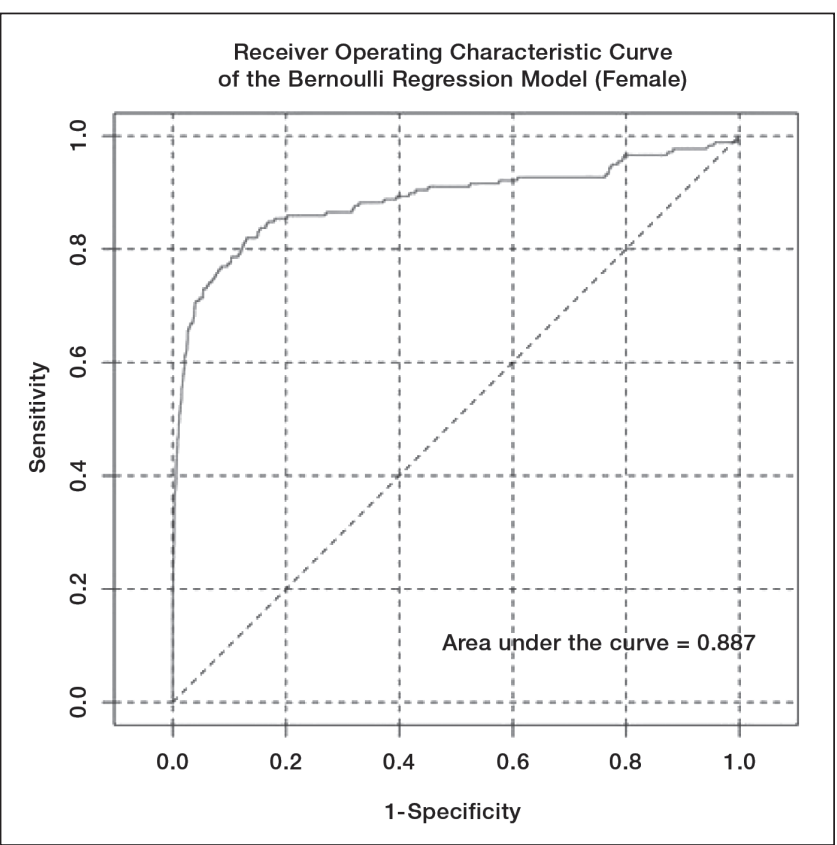

Figure 2) ROC curve for the Bernoulli regression output for women to predict $\mathrm{C} 282 \mathrm{Y}$ homozygotes in 27,486 Caucasian women from the Hemochromatosis and Iron Overload Screening (HEIRS) Study. The area under the curve was 0.887 and the Nagelkerke pseudo R-squared was 0.34

\section{DISCUSSION}

The present study used a large primary care-based population study to create regression equations to predict the C282Y genotype of hemochromatosis. A novel aspect of the study was the development of predictive smartphone application and a web-based calculator.

Despite the large sample size and high area under the curve values, the individual predictive probabilities have wide CIs. This reflects both the relative paucity of $\mathrm{C} 282 \mathrm{Y}$ homozygotes in the primary carebased sample and the number of conditions other than HFE mutations that affect transferrin and ferritin. Specifically, there are some C282Y homozygotes with normal transferrin saturation and ferritin levels, and many more participants with elevations in transferrin saturation and/or ferritin who do not have the $\mathrm{C} 282 \mathrm{Y}$ genotype. With a high transferrin saturation and serum ferritin level, there are fewer non-C282Y homozygotes with this same pattern of tests; therefore, the probability is higher. At lower transferrin saturation and serum ferritin values, there are many more non-C282Y homozygotes in the populationbased sample who may have elevated values secondary to inflammation, fatty liver, chronic alcohol ingestion and obesity.

These tools are for the prediction of the C282Y genotype, which is not synonymous with the prediction of iron overload. It is not possible to perform this analysis for iron overload because an independent measure of iron status is not available in the population sample. We have previously reported on the use of transferrin saturation values to predict hepatic iron overload in a significantly smaller sample (5). It also is unlikely that fasting blood samples would have improved the predictions because we previously demonstrated no improvement of fasting transferrin saturation over random samples to predict the C282Y genotype (6). Transferrin saturation also has considerable biological variability, which limits its value as a screening test (7).

Many physicians will overestimate the probability of hemochromatosis because they may be unaware of the low specificity of transferrin saturation and ferritin values for hereditary hemochromatosis. A recent subanalysis from the HEIRS Study (8) demonstrated that only $10 \%$ to $12 \%$ of the participants with an elevated serum ferritin level

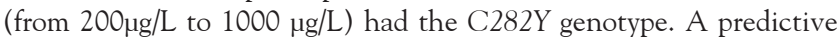




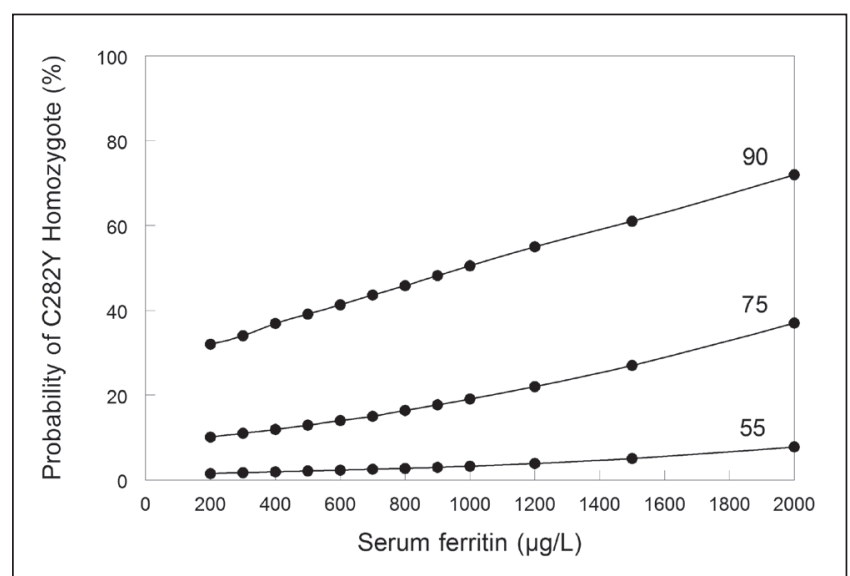

Figure 3) Probability of being a C282Y homozygote increases as serum ferritin level increases in Caucasian men. The figure illustrates patients with a transferrin saturation of $55 \%, 75 \%$ and $90 \%$. Data were generated from the Bernoulli regression equation for men from the population-based Hemochromatosis and Iron Overload Screening (HEIRS) Study

tool could focus the use of the hemochromatosis genetic test on participants with a high probability to avoid unnecessary testing costs and reduce the potential for adverse effects of genetic testing such as stigmatization and, less commonly, genetic discrimination (9). As with many screening tests, the utility of this tool is optimal at the low and high ends of the test value, with the middle values less informative. A patient with a low predicted probability could be evaluated first for other more common causes of an elevated serum ferritin level, and retested to determine whether the values change over time. A patient with a high probability should move directly to the genetic test. These equations are not intended to pre-empt the genetic test. They may be a useful clinical guide based on a large population-based sample, which reminds clinicians that there are many other causes of elevations in serum ferritin level and transferrin saturation that are not related to hemochromatosis.

DISCLOSURES: The authors have no financial disclosures or conflicts of interest to declare.

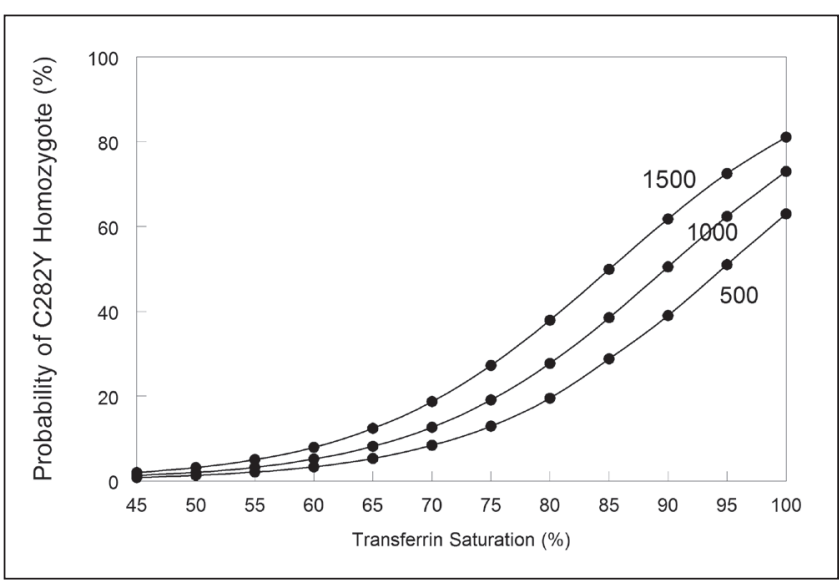

Figure 4) Probability of being a C282Y homozygote increases as serum transferrin saturation increases in Caucasian men. The figure illustrates patients with serum ferritin levels of $500 \mu \mathrm{g} / \mathrm{L}, 1000 \mu \mathrm{g} / \mathrm{L}$ and $1500 \mu \mathrm{g} / \mathrm{L}$. Data were generated from the Bernoulli regression equation for men from the populationbased Hemochromatosis and Iron Overload Screening (HEIRS) Study

\section{REFERENCES}

1. Adams PC, Reboussin DM, Barton JC, et al. Hemochromatosis and iron-overload screening in a racially diverse population. N Engl J Med 2005;352:1769-78.

2. Cherfane CE, Hollenbeck RD, Go J, Brown KE. Hereditary hemochromatosis: Missed diagnosis or misdiagnosis? Am J Med 2013;126:1010-5

3. McGrath J, Deugnier Y, Moirand R, Jouanolle A, Chakrabarti S, Adams P. A nomogram to predict C282Y hemochromatosis. J Lab Clin Med 2002;140:6-8.

4. McLaren CE, Barton JC, Adams PC, et al. Hemochromatosis and Iron Overload Screening (HEIRS) Study design for an evaluation of 100,000 primary care-based adults. Am J Med Sci 2003;325:53-62.

5. Beaton M, Adams PC. Transferrin saturation as a predictor of hepatic iron overload. Liver Int 2011;31:272-3.

6. Adams P, Zaccaro D, Moses G, et al. Comparison of the unsaturated iron binding capacity with transferrin saturation as a screening test to detect C282Y homozygotes for hemochromatosis in 101,168 participants in the HEIRS study. Clin Chem 2005;51:1048-51.

7. Adams PC, Reboussin DM, Press RD, et al. Biological variability of transferrin saturation and unsaturated iron binding capacity. Am J Med 2007;120:999.e1-e7.

8. Adams PC, Speechley M, Barton JC, McLaren CE, McLaren GD, Eckfeldt JH. Probability of C282Y homozygosity decreases as liver transaminase activities increase in participants with hyperferritinemia in the hemochromatosis and iron overload screening study. Hepatology 2012;55:1722-6.

9. Hall MA, Barton JC, Adams PC, et al. Genetic screening for iron overload: No evidence of discrimination at one year. J Fam Practice 2007;56:829-33. 


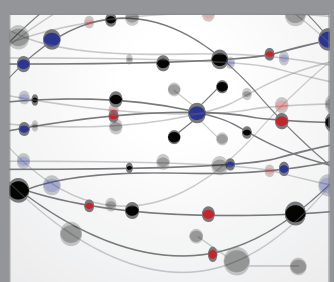

The Scientific World Journal
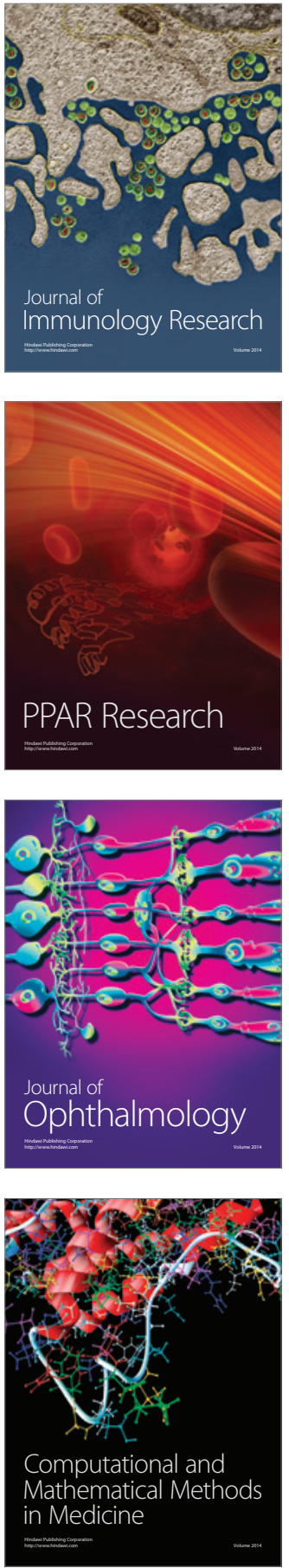

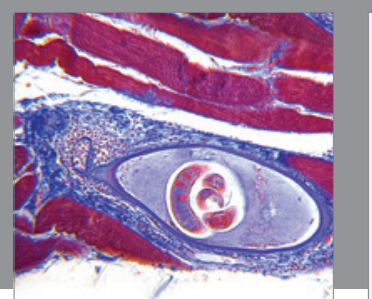

Gastroenterology Research and Practice

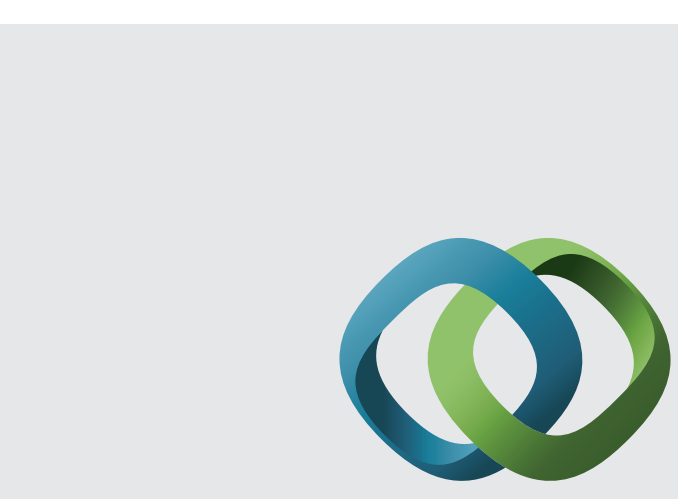

\section{Hindawi}

Submit your manuscripts at

http://www.hindawi.com
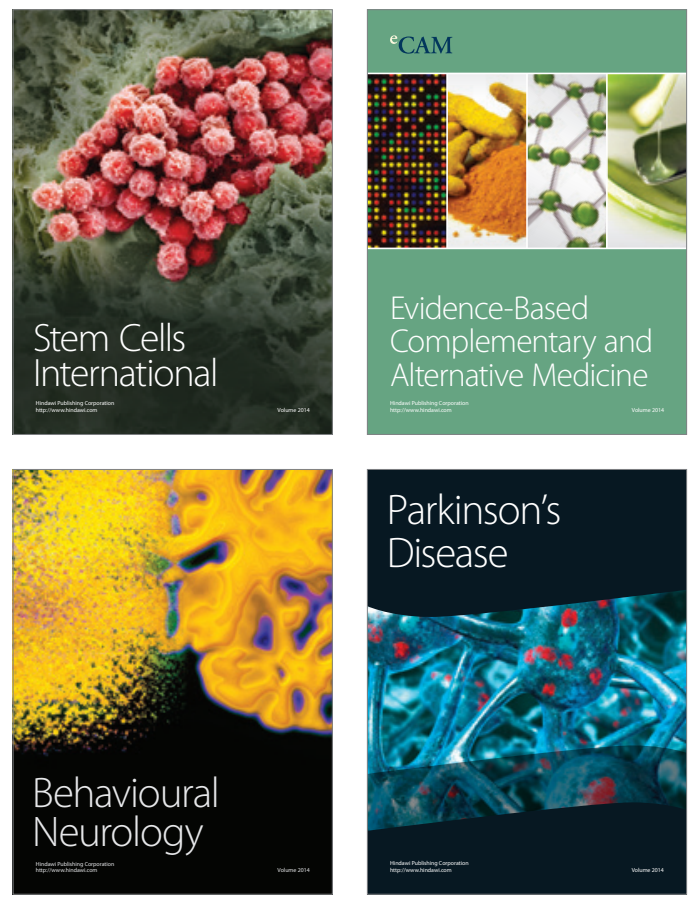
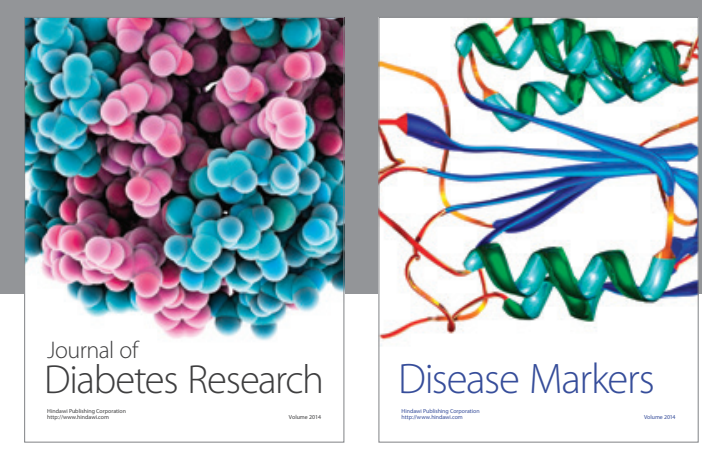

Disease Markers
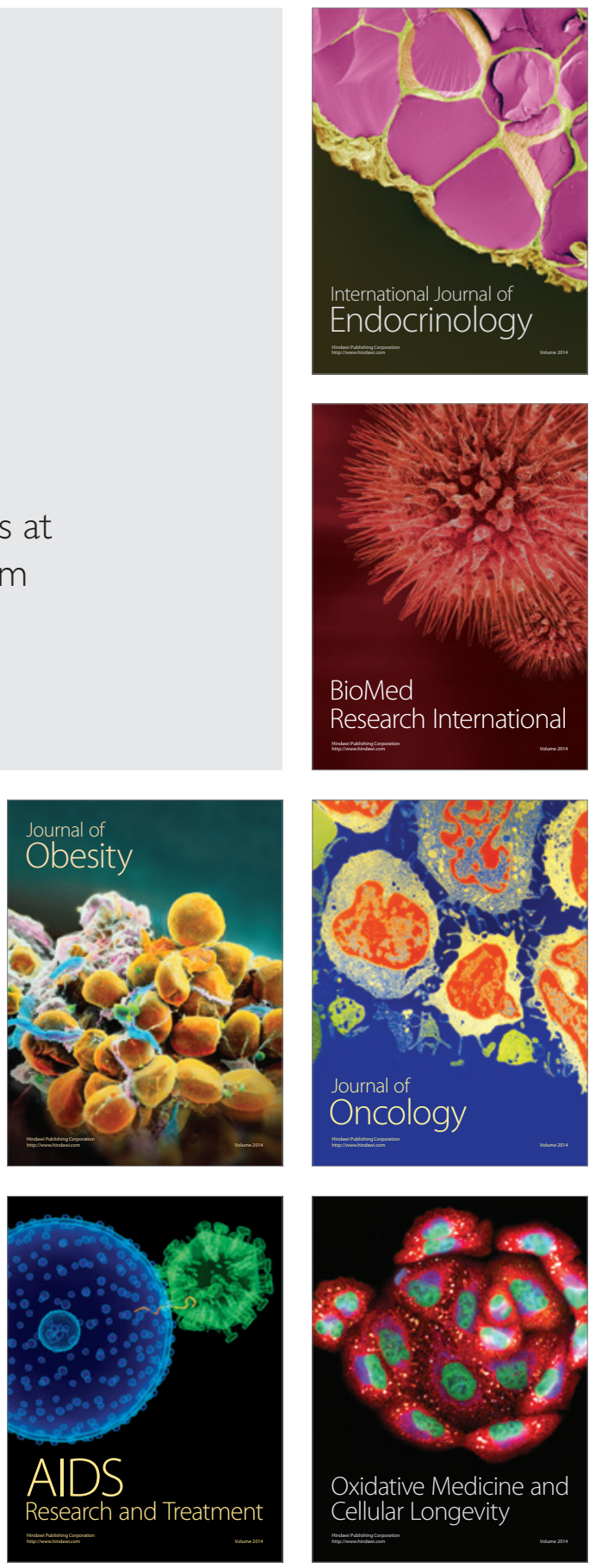